ENCYCLOPEDDIE Encyclopédie berbère

BERBERE

18 | 1997

18 | Escargotière - Figuig

\title{
Feraoun Mouloud
}

\section{J. Déjeux}

\section{OpenEdition}

Journals

Édition électronique

URL : http://journals.openedition.org/encyclopedieberbere/2033

DOI : 10.4000/encyclopedieberbere.2033

ISSN : 2262-7197

\section{Éditeur}

Peeters Publishers

\section{Édition imprimée}

Date de publication : 1 août 1997

Pagination : 2763-2765

ISBN : 2-85744-948-8

ISSN : 1015-7344

\section{Référence électronique}

J. Déjeux, «Feraoun Mouloud », Encyclopédie berbère [En ligne], 18| 1997, document F16, mis en ligne le 01 juin 2011, consulté le 24 septembre 2020. URL : http://journals.openedition.org/ encyclopedieberbere/2033; DOI : https://doi.org/10.4000/encyclopedieberbere.2033

Ce document a été généré automatiquement le 24 septembre 2020

(C) Tous droits réservés 


\section{Feraoun Mouloud}

\section{J. Déjeux}

1 Le vrai nom - ancien - de la famille de cet écrivain d'origine Kabyle était Aït-Chaâbane (après 1871, les listes d'état civil furent établies en commençant par les lettres de l'alphabet français). Mouloud Feraoun est né le 8 mars 1913 à Tizi-Hibel près de Taguemount-Azouz en Grande Kabylie. Fils de paysans, son père était véritablement un gueux et avait toujours trimé, écrivait Feraoun lui-même à son ami, le romancier Emanuel Roblès. Il avait travaillé à Gafsa, Bône, Constan-tine et était parti pour la France en 1910. Il resta assez longtemps à Lens où il fut mineur. Il fit une vingtaine de voyages entre la France et l'Algérie; le dernier séjour, en 1927-1928, se termina par un accident aux fonderies d'Aubervilliers que Feraoun a relaté dans Le Fils du pauvre. Cet homme courageux avait fait à pied, par exemple, le trajet de Tizi-Hibel à Tunis. Il ne savait ni lire ni écrire. Il mourut en 1958.

2 Mouloud Feraoun a raconté sa propre enfance dans le récit en grande partie autobiographique, Le Fils du Pauvre. A sept ans, il entre à l'école à Taourirt-Moussa à deux kilomètres de son village natal. Grâce à une bourse d'enseignement, il entre en 1928 au collège de Tizi-Ouzou et prend pension à la Mission Rolland dans cette même ville. Reçu en 1932 au concours de l'École Normale de Bouzaréa (Alger), il commence cette année-là les études qui doivent le conduire à la profession d'instituteur. Il collabore à une modeste revue, Le Profane, dirigée par Emmanuel Roblès. En 1934, il est exempté du service militaire par tirage au sort, selon le code de l'Indigénat.

En 1935, Mouloud Feraoun est nommé instituteur dans son village natal, puis à Taourirt-Moussa. En 1952, il prend la direction du cours complémentaire de FortNational (actuellement Larbaa Nath-Iraten). Il avait effectué son premier voyage à Paris en 1949 et en 1951, il avait échangé ses premières lettres avec Albert Camus. La guerre de libération éclatant le $1^{\text {er }}$ novembre 1954, Feraoun commence à écrire son Journal en 1955. En juillet 1957, il est nommé directeur de l'école de Nador au Clos-Salembier à Alger. En 1960 (octobre), il accepte le poste d'inspecteur des Centres sociaux (à El Biar) fondés par Germaine Tillion dans un but éducatif des milieux algériens défavorisés. Il voyage en Italie, Sardaigne et Grèce en mai-juin 1961, avec une mission d'études du Centre algérien d'expansion économique et sociale. Le 15 mars 1962, il est assassiné à El 
Biar par un commando de l'O.A.S. avec deux autres Algériens (Ali Hamoutène et Salah Ould Aoudia) et trois Français (Max Marchand, Marcel Aymard et Marcel Basset), lors d'une réunion à laquelle devait prendre part également le Commissaire Général à la Jeunesse et aux Sports, Petitbon. Il a été inhumé à Tizi-Hibel.

Mouloud Feraoun s'était marié en 1935 à l'une de ses cousines, Dehbia et était père de sept enfants.

5 Son œuvre littéraire est très enracinée dans le terroir kabyle, mais ses résonances humaines sont universelles. Ses trois romans sont bien connus et sont parmi les plus lus de la littérature maghrébine de langue française. Le Fils du Pauvre, commencé en avril 1939 pendant les vacances de Pâques, paraît à compte d'auteur en 1950 aux Cahiers du Nouvel Humanisme au Puy (après un essai aux Nouvelles Éditions Latines à Paris). Feraoun avait recopié trois fois son manuscrit, à la main et de bout en bout, avant de l'envoyer à l'éditeur. L'ouvrage a été réédité en 1954 aux éditions du Seuil (Paris), amputé d'environ soixante-dix pages (la fin du volume). Ce roman est le récit de l'enfance de Menrad, instituteur Kabyle ; à quelques détails et événements près, la vie du jeune Fouroulou fut celle de Mouloud Feraoun. La Terre et le Sang paraît en 1953 au Seuil. Ce second roman, centré sur rémigration des travailleurs algériens en France et sur le retour de l'un d'eux au village natal accompagné de son épouse française, obtient le Prix populiste. Le Fils du Pauvre lui avait valu le Grand prix littéraire de la ville d'Alger en décembre 1950. Selon des chroniques de Jean Sénac dans Oran républicain (en 1946) et L'Africain (en 1947), Feraoun avait posé en 1946 sa candidature pour le Grand prix littéraire de l'Algérie en présentant le manuscrit de "Menrad, instituteur kabyle". Le troisième roman, Les Chemins qui montent, paraît également au Seuil en 1957. Nous sommes en pleine guerre; ce roman est celui du malaise des jeunes (sans doute aussi celui du romancier dans sa situation d'écrivain et d'instituteur), tout en nous contant les amours malheureuses d'Amer pour Dehbia; cet Amer, en porte-à-faux dans sa société, était le fils de la Française du second roman. Enfin, Mouloud Feraoun avait commencé à écrire un autre roman, L'Anniversaire, terminé en 1959. Un Kabyle devenait amoureux d'une Française. Non satisfait, l'auteur entreprenait en 1961 une nouvelle version de ce roman, dont quatre chapitres seulement (achevés) ont paru en 1972. L'Anniversaire (Le Seuil) contenait encore d'autres textes divers et la fin du Fils $d u$ Pauvre, non reprise dans la réédition de 1954.

6 Jours de Kabylie est un recueil de récits, de scènes et de portraits puisés dans la montagne kabyle et joliment illustrés par Brouty (Alger, Baconnier, 1954 ; réédit. Paris, Le Seuil, 1968). Le Journal, 1955-1962, paraît en 1962 (Le Seuil), tandis que les Lettres à ses amis (allant de 1949 à 1962) sont publiées en 1969 (Le Seuil). Fort instructives, elles nous apprennent beaucoup sur l'homme et sur l'œuvre.

7 Il faut ajouter des textes sur des sujets variés tels que l'école française, l'instituteur du bled, sur le problème algérien, sur ses amis EmmanuelRoblès et Albert Camus. Des contes et légendes paraissaient dans Algeria, Soleil (Alger). Feraoun avait publié aussi une traduction partielle des Poèmes de Si Mohand (édit. de Minuit) précédés d'un essai sur le poète. La Revue des Centres sociaux avait accueilli enfin "L'entraide dans la société Kabyle" et "Le voyage en Grèce", textes repris dans le volume L'Anniversaire.

8 L'œuvre romanesque de Feraoun se situe dans le courant de la littérature maghrébine de langue française appelé assez couramment "ethnographique" et quelque peu dévalorisé par les lecteurs maghrébins d'aujourd'hui. Ecrite en fonction de lecteurs européens pour leur dire : «Voilà ce que nous sommes » de notre côté, nous Algériens, 
pour répondre à l'image que les Français présentaient et aussi à celle, déformée, qu'ils donnaient du Maghrébin colonisé, cette œuvre n'en révèle pas moins un témoin authentique de sa société et de son temps.

D'une façon précise, le projet initial de Feraoun était de "traduire l'âme kabyle" : «Bien qu'on sache que les Kabyles sont des hommes comme les autres, je crois, voyez-vous que je suis bien placé pour le dire ", expliquait-il dans une interview en 1953. Autour des années 50 déjà, les romanciers maghrébins ne supportaient plus, avec raison, d'être décrits par d'autres, de l'extérieur, par Ferdinand Duchène par exemple, romancier colonial et régionaliste. Mouloud Feraoun veut donc nous "faire voir" sa propre société, de l'intérieur. D'où le grand intérêt sociologique de son œuvre où trois grands thèmes dominent: la terre natale, la condition humaine en Grande kabylie, les travailleurs algériens émigrés en France. Manières de vivre, coutumes, croyances, travaux et jours, aspects divers de la psychologie sociale sont peints avec exactitude, recoupant et complétant les descriptions données par d'autres romanciers comme Mouloud Mammeri et Malek Ouary. Tout en tenant compte naturellement de l'aspect esthétique et du travail propre au romancier, une lecture sociologique de ces romans est donc possible; elle constitue un enrichissement certain. Cependant, l'ambiance parfois misérabiliste qui s'en dégage ne plaît guère, parce que peu enthousiasmante pour le jeune Maghrébin d'aujourd'hui qui se veut tourné vers l'avenir. Il n'en reste pas moins que, replacée dans son temps, cette œuvre demeure importante sur le plan psychologique et humain, dépassant largement les frontières sur ce plan-là. Et de ce point de vue, elle apporte une connaissance sympathique de la vie dans une société berbère en mutation.

10 Un compatriote de Feraoun, Belaïd Ait-Ali, auteur de contes et de poèmes, écrivait en 1950 que seul un Kabyle pourrait décrire et dépeindre objectivement les Kabyles " parce que seul il a accès à certains coins de l'âme de ses... cousins ». C'est bien ce que Feraoun a réussi à faire.

11 Le Journal et les Lettres ne sont pas moins importants à cause des observations lucides et honnêtes sur la société kabyle à travers la guerre d'indépendance. Ces notations sont sans doute fragmentaires; elles sont cependant des documents de premier plan. Homme déchiré par le conflit, homme-frontière du fait de son acculturation et de son statut d'instituteur, Feraoun voulait se situer "au-dessus des haines".

De même que des romans italiens comme ceux de Carlo Levi, Ignatio Silone, Elio Vittorini, ont dévoilé aux lecteurs la misère et la dure condition humaine des paysans de Lucanie, des Abruzzes ou de Sicile, de même les romans de Mouloud Feraoun (comme ceux de Mohammed Dib qui s'inspire explicitement de ces auteurs italiens), ont contribué au dévoilement des sociétés colonisées et d'images nouvelles inconnues. Cela avant même que des sociologues parviennent jusqu'à ces profondeurs, ou parce que trop étrangers à la vie de ces sociétés. L'œuvre de Gorki éclaire certes davantage les conditions du surgissement d'une conscience prolétarienne. Mouloud Feraoun, à travers son œuvre, sans doute trop statique, a voulu nous montrer que sa vie et celle des siens valaient la peine d'être connues. En même temps, l'Algérie (et le monde berbère) était "nommée" par l'un des siens et faisait son entrée dans les lettres maghrébines de langue française. 


\section{BIBLIOGRAPHIE}

DEJEUX J.,Littérature maghrébine de langue française, Sherbrooke, Québec, Canada, 1973, p. 114-142.

DEJEUX J., “Hommage à Mouloud Feraoun”, Les Lettres françaises, n 919, 22-28 mars 1962.

KHATIBI A., Le Roman maghrébin, Paris, Fr. Maspéro, coll. “Domaine maghrébin”, 1968, p. 49-51.

PANTUCEK S., La Littérature algérienne moderne, Prague, Institut oriental, 1969, p. 109-114.

ROBLES E., Dossier d'auteur : “Mouloud Feraoun”, Présence francophone, $\mathrm{n}^{\circ} 1$, Sherbrooke, Québec,

Canada, Automne 1970, p. 147-160.

INDEX

Mots-clés : Biographie, Littérature 